\title{
GENDER DIFFERENCE IN PRESENTATION, MANAGEMENT AND INHOSPITAL MORTALITY IN ST ELEVATION MYOCARDIAL INFARCTION IN A TERTIARY CARDIAC CENTER
}

\author{
Hemant Shrestha, Arun Sayami, Om Murti Anil, Chandramani Poudel, \\ Ratnamani Gajurel, Sanjeev Thapa
}

\begin{abstract}
Background: Studies have shown that women are less likely to receive reperfusion therapy and have higher inhospital death in ST Elevation myocardial infarction(STEMI) as compared to men. This study aims to examine presentation, acute therapy, and inhopital mortality in women admitted with diagnosis of acute STEMI in a tertiary care cardiac center.
\end{abstract}

Methods: Patients admitted with diagnosis of acute STEMI from $1^{\text {st }}$ June 2013 to $31^{\text {st }}$ May 2015 were included in the study. Gender difference in baseline characterstics, comorbidities, prehospital delay, type of treatment received and inhospital death were measured. Variables that might have impact on inhospital deaths were analyzed on multivariate regression analysis to find out other variables adjusted effect of gender on inhospital deaths.

Results : Majority of the patients were men (Men 69\% vs women 31\%). Women were older, were more likely to be diabetics and smoker. Prehospital delay was more in women ( women 22 hours vs men 12 hours, $\mathrm{p}$ value- 0.02 ). About $46 \%$ of both men and women received reperfusion therapy. There was more inhospital mortality in women (women $13.5 \%$ vs men $6.5 \%$, p value 0.02). Women had more inhospital mortality even after adjustment with other covariables $(\mathrm{OR}=$ $3.110,95 \% \mathrm{CI}=1.411-6.902$, $\mathrm{p}$ value-0.005).

Conclusion : Women were more likely to be elderly, diabetics, smoker and presented later than men after symptoms onset. Women received reperfusion therapy similar to that of men. After adjustment with other covariates, women remained a significant variable to inhospital death.

Key Words: Gender difference, ST elevation myocardial infarction, prehospital delay, reperfusion therapy, inhospital mortality.

\section{INTRODUCTION}

Coronary artery disease is the leading cause of death in both men and women worldwide. ${ }^{1}$ Number of studies has shown that there is gender difference in presentation, management and outcome in acute coronary syndrome. ${ }^{2-6}$ Some studies have shown that females are less likely to receive reperfusion therapy in ST Elevation myocardial
infarction(STEMI) as compared to males. $^{2,3}$ Other studies report that women who present with acute myocardial infarction have worse in-hospital and long-term prognoses than men. ${ }^{4-6}$ It is uncertain whether these differences reflect differences in base-line characteristics or pathophysiologic distinctions between men and women. ${ }^{7}$ 
Part of the difference in mortality between gender is accounted for by the older age of and higher prevalence of comorbidities in women. $^{5}$ Less frequent use of revascularization procedures in women also may account for some of the excess mortality. Findings from large database studies ${ }^{6,8-10}$ have indicated that women with acute myocardial infarction tend to undergo less aggressive hospital management than men. The aim of this study was to examine presentation, acute therapy, and inhopital mortality in women as compared to men admitted with diagnosis of acute STEMI in a tertiary care cardiac center.

\section{METHODS}

All admitted patients both male and female diagnosed as acute STEMI in Department of Cardiology, Manmohan Cardiothoracic Vascular and Transplant center(MCVTC), Kathmandu, were enrolled in the study. The study period was from $1^{\text {st }}$ June 2013 to $31^{\text {st }}$ May 2015. Acute STEMI was diagnosed on the basis of third universal definition of myocardial infarction. ${ }^{11}$ STEMI was defined by characteristic symptoms of myocardial ischemia in association with persistent electrocardiographic (ECG) ST elevation and subsequent release of biomarkers of myocardial necrosis. ECG criteria for ST elevation : New ST elevation at the $\mathrm{J}$ point in at least 2 contiguous leads of $\geq 2 \mathrm{~mm}(0.2$ $\mathrm{mV})$ in men or $\geq 1.5 \mathrm{~mm}(0.15 \mathrm{mV})$ in women in leads V2-V3 and/or of $\geq 1 \mathrm{~mm}(0.1$ $\mathrm{mV}$ ) in other contiguous chest leads or the limb leads. ${ }^{11}$. Baseline demographic data and a complete clinical history were taken from each patient. Past medical history, drug history, smoking and alcohol intake history was taken. General and systemic examination of the patient was done. Comorbid conditions included hypertension, diabetes mellitus, renal dysfunction, dyslipidemia, stroke and smoking. Prehospital delay was defined as the time between onset of STEMI and hospital arrival. Killip class of each patient was recorded at presentation. ${ }^{12}$

Patients were tried to be treated under guidelines given by ACC/AHA in 2013. ${ }^{13}$ Depending upon the time duration at which patients presented, there were three groups of patients: primary PCI, thrombolysis and conservative management. Primary PCI was performed in those patients presenting within 12 hours of symptoms onset, evidence of ongoing ischemia within 12-24 hours of symptoms onset and presenting in cardiogenic shock irrespective of duration of symptoms. If patients didn't give consent for PCI, then either thrombolysis was performed or was kept in conservative management. Thrombolysis was performed with streptokinase or tenecteplase in patients presenting within 12 hours and evidence of ongoing ischemia 12-24 hours of symptom onset. Patients presenting after 24 hours and not in cardiogenic shock were managed conservatively with medications.

The outcome variable was death during index hospital admission.

\section{STATISTICAL ANALYSIS}

Statistical analysis was performed with SPSS version 20. For demographic profile, frequency and percentage distribution were obtained for each variable. Data were expressed as mean $\pm \mathrm{SD}$ for continuous variables and as percentage for categorical variables. For continuous variables, differences between groups were compared with independent t-test. The frequencies of categorial variables in 2 populations were compared by chi-square test and by calculating the odds ratios (OR) and 95\% confidence intervals (CI). Variables influencing inhospital mortality were assessed first with the aid of univariate regression analysis. Multivariable logistic-regression model was used to determine, after adjusting 
for base-line differences, the effect of sex on the rates of mortality.

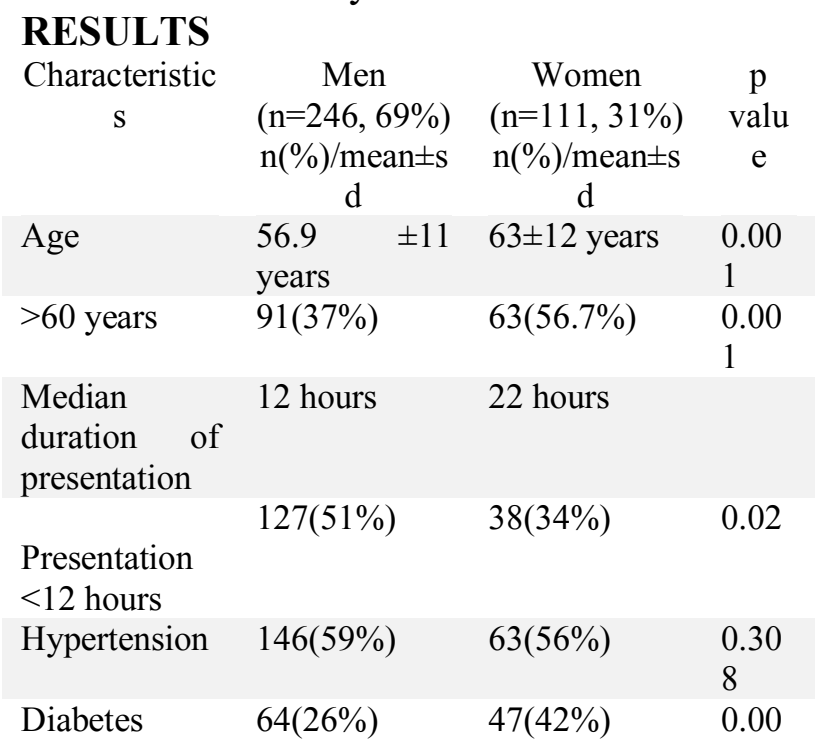

Table 1: Baseline characteristics, management and mortality of patients

\section{Baseline Characterstics}

A total of 356 patients were enrolled in the study. More than two third of the patients were men (69\% vs 31\%). Mean age of women were about 6 years more than that of men (63 vs $56.9 \mathrm{yrs}$ ). Smoking and history of diabetes were more prevalent in women.

\section{Prehospital delay}

Both men and women had long prehospital delay. Median duration of presentation to hospital after symptoms onset was 10 hours more in women. More than fifty percent of men presented within 12 hours of symptoms onset while only one third of women presented within 12 hours of symptom onset.

\section{Management}

Overall less than fifty percent of patients received reperfusion therapy. Reperfusion was similar in both men and women (men 46.4\%, women 46.8\%). Both groups received primary PCI equally (men $26.4 \%$, women $27 \%$ ). Among patients who presented within 12 hours, the rate of

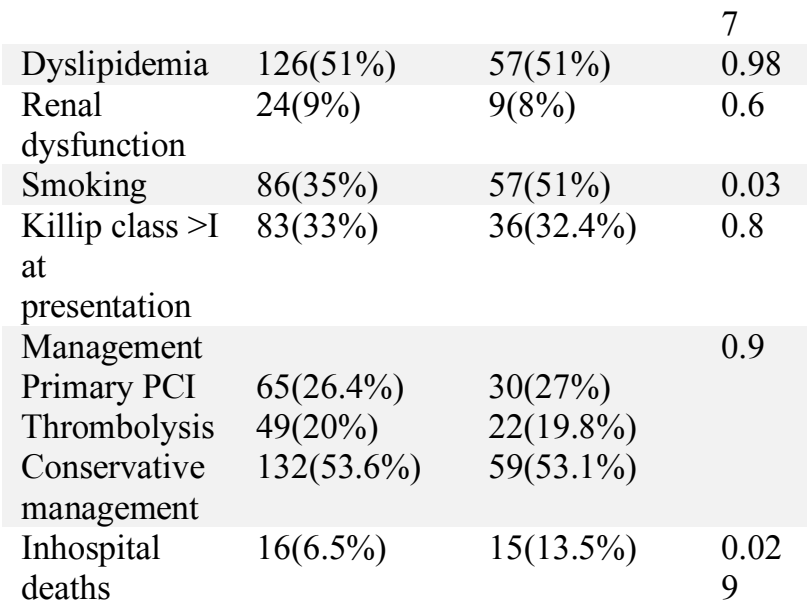

reperfusion therapy was similar in both groups.( Men 87\%, women 90\%).

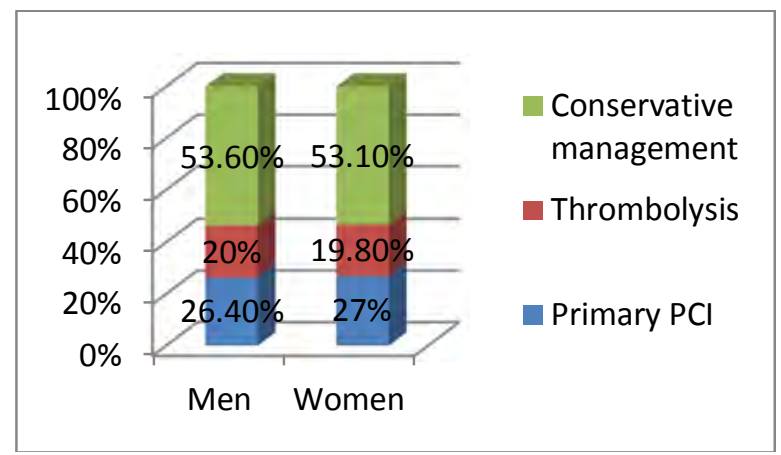

Fig 1: Management of patients

\section{Inhospital mortality}

Overall inhospital death was $8.7 \%$. Inhospital death was more than two times in women than in men $(13.5 \%$ vs $6.5 \%$, p value0.02). Besides sex, nine other variables ( duration of presentation $>12$ hours, age $>60$ years, hypertension, diabetes, dyslipidemia, renal dysfunction, smoking, killip class at presentation $>\mathrm{I}$ and lack of reperfucion therapy) were assessed in univariate analysis with outcome as inhospital death. Women, DOP $>12$ hours, age $>60$ years and Killip 
class at presentation $>I$ were variables that have significant effect on inhospital deaths. After adjusting these variables in multivariate analysis, women were still a significant variable that have impact in inhospital death (p value 0.005). Beside women, only Killip class $>$ I had adjusted significant impact on inhospital death.

\begin{tabular}{|c|c|c|c|}
\hline Variables & OR & $\begin{array}{l}95 \% \quad \mathrm{CI} \\
\text { of OR }\end{array}$ & $\mathrm{p}$ value \\
\hline Female Sex & 2.24 & $\begin{array}{l}1.06- \\
4.725\end{array}$ & 0.02 \\
\hline $\begin{array}{lr}\text { Duration } & \text { of } \\
\text { presentation } & >12 \\
\text { hours } & \end{array}$ & 2.243 & $\begin{array}{l}1.002- \\
5.019\end{array}$ & 0.04 \\
\hline Age $>60$ years & 2.605 & $\begin{array}{l}1.209- \\
5.016\end{array}$ & 0.015 \\
\hline Hypertension & 1.12 & $\begin{array}{l}0.734- \\
1.709\end{array}$ & 0.598 \\
\hline Diabetes Mellitus & 1.369 & $\begin{array}{l}0.939- \\
1.994\end{array}$ & 0.102 \\
\hline Dyslipidemia & 1.564 & $\begin{array}{l}0.735- \\
3.320\end{array}$ & 0.245 \\
\hline Renal dysfunction & 2.047 & $\begin{array}{l}0.729- \\
5.747\end{array}$ & 0.174 \\
\hline Smoking & 1.671 & $\begin{array}{l}0.758- \\
3.499\end{array}$ & 0.173 \\
\hline Killip Class $>$ I & 4.886 & $\begin{array}{l}2.219- \\
10.578\end{array}$ & 0.001 \\
\hline $\begin{array}{l}\text { Lack of reperfusion } \\
\text { therapy }\end{array}$ & 0.984 & $\begin{array}{l}0.640- \\
1.513\end{array}$ & 0.9 \\
\hline
\end{tabular}

Table 2: Univariate analysis of different variables on inhospital mortality.

\begin{tabular}{|c|c|c|c|}
\hline Variables & OR & $\begin{array}{l}95 \% \mathrm{CI} \text { of } \\
\text { OR }\end{array}$ & $\mathrm{p}$ value \\
\hline Female sex & 3.110 & $\begin{array}{l}1.411- \\
6.902\end{array}$ & 0.005 \\
\hline $\mathrm{ss}>\mathrm{I}$ & .515 & $2.46-12.36$ & 0.001 \\
\hline
\end{tabular}

Table 3: After multivariate analysis of effects of different variables on inhospital mortality

\section{DISCUSSION}

More than two third of the patients were men. It was similar to a registry in Germany, Heer T. found that men were predominant $(70 \%)$ than women. ${ }^{6}$ Men were also predominant in studies conducted in Nepal. In Kathmandu, men were $82 \%,{ }^{14}$ in Pokhara $51.7 \%{ }^{15}$ and in the Western Nepal ACS registry 62.3\%. ${ }^{16}$
Women were about 6 years older than men. This finding was also similar to other studies internationally and in Nepal. ${ }^{4}, 6,15-17$

In accordance to other studies ${ }^{4},{ }^{6,17-18}$ diabetes was more common in women. But in study conducted in Pokhara, Parajuli M found that diabetes was more common in men $(15 \%$ vs $10 \%)$. Overall smoking was highly prevalent $(40 \%)$ in our study in both gender. It is similar to other studies where it varied from $55-80 \%$.4,14-16 In contrast to other studies, ${ }^{4,15}$ smoking was more prevalent in women as compared to men (51\% vs $35 \%$, p value 0.03 ). This shows higher prevalence of smoking in women with STEMI and as this is one of the major risk facor for CAD, every effort should be applied so as to help quit smoking. Besides these, there were no significant difference in hypertension, dyslipidemia, renal dysfunction and Killip Class $>1$ at presentation between men and women.

The median prehospital delay was 16 hours. Only half of the men and one third of the women presented within 12 hours of symptoms onset. This is quite high as compared to other studies. The median PHT is 3.5 hours in the USA and 2.5 hours in the United Kingdom, but 4.4 hours in South Korea and 4.5 hours in Japan ${ }^{19}$ and in India 5.3 hours. $^{20}$ The median prehospital delay in our study was even more in women (22 hours vs 12 hours, $\mathrm{p}$ value 0.02 ). The outcome of treatment is directly dependent upon the early reperfusion therapy, longer prehospital delay have poorer outcome. ${ }^{13}$ The cause of longer prehospital delay should be studied moreover in women so as to decrease prehospital delay and to achieve better outcome.

With regard to reperfusion treatment, only $46.6 \%$ of the patients received reperfusion therapy overall. Women received reperfusion therapy equally to men in our study $(46.8 \%$ vs $46.4 \%)$. Primary $\mathrm{PCI}(27 \%$ vs $26.4 \%)$ and thrombolysis $(19.8 \%$ vs $20 \%)$ was also similar. This is in contrast to other studies 
where women were less likely than men to undergo intravenous thrombolysis and invasive cardiac reperfusion procedures. ${ }^{6,22} \mathrm{In}$ MITRA registry $48.6 \%$ of women received reperfusion therapy as compared to $62.5 \%$ of men. ${ }^{6}$ This study shows that women received reperfusion therapy equal to men.

Consistent with most previous investigations, ${ }^{6,22-23}$ women in our study had a higher risk for hospital death after STEMI than men(13.5\% vs $6.5 \%$, $p$ value 0.02 ). The Global Utilization of Streptokinase and t-PA for Occluded Coronary Arteries-I (GUSTO-I) angiographic study found gender to be an independent predictor of 30-day mortality after adjustment for clinical variables. $^{24}$ In the Myocardial Infarction Triage and Intervention Trial (MITI) registry, Kudenchuk PJ found that female gender independently predicted almost a doubling of hospital mortality. ${ }^{25}$ After adjusting for age and in combination with other variables, including clinical risk factors and acute reperfusion strategies, we still found a gender difference in hospital mortality, with higher mortality rates in women.( $p$ value - 0.005). The cause of increased mortality in women can be attributed to older age, more comorbid conditions and delayed presentation to hospital.

\section{LIMITATIONS}

The data represents from only one center in Nepal, so its results cannot be generalized to rest of country. Many of the patients were referred from other hospitals which might be the reason for longer prehospital delay. Patients who expired in emergency room and who were not admitted were not included in the study.

\section{CONCLUSION}

More than two third of the patients were men. Women were likely to be diabetic and smokers. Women presented to hospital significantly later than men after symptom onset. Women received reperfusion therapy similar to that of men. Inhospital mortality was more in women. Women and Killip class at presentation $>$ I were significant predictor of inhospital death after adjustment with other variables.

\section{REFERENCES}

1. Roger VL, Go AS, Lloyd-Jones DM, et al, for the American Heart Association Statistics Committee and Stroke Statistics Subcommittee. Heart disease and stroke statistics - 2012 update: a report from the American Heart Association. Circulation 2012;125:e2-220.

2. Radovanovic D, Erne P, Urban P, et al. Gender differences in management and outcomes in patients with acute coronary syndromes: results on 20,290 patients from the AMIS Plus Registry. Heart 2007;93:1369-75.

3. Ayanian JZ, Epstein AM. Differences in the use of procedures between women and men hospitalized for coronary heart disease. N Engl J Med 1991;325:221-5.

4. Akhter N, Milford-Beland S, T. roe $M$ et al. Gender differences among patients with acute coronary syndromes undergoing percutaneous coronary intervention in the American College of CardiologyNational Cardiovascular Data Registry (ACC-NCDR). Circulation. 2007;115:833-839.

5. Vaccarino V, Krumholz HM, Berkman LF, Horwitz RI. Sex differences in mortality after myocardial infarction: is there evidence for an increased risc for women? Circulation 1995;91:1861-1871.

6. Heer $\mathbf{T}$, Schiele $\mathbf{R}$, Scheider $\mathbf{S}$ et al. Gender Differences in Acute Myocardial Infarction in the Era of Reperfusion (The MITRA Registry). Am J Cardiol 2002;89:511-517.

7. Hochman JS, Tamis JE, Thompson TD et al. Sex, Clinical presentation, and outcome in patients with Acute Coronary syndromes. N Engl J Med 1999;341:226-32.

8. Hanratty B, Lawlor DA, Robinson MB, Sapsford RJ, Greenwood D, Hall A. Sex differences in risk factors, treatment and mortality after acute myocardial infarction: an observational study. $\mathrm{J}$ Epidemiol Community Health. 2000;54:912-916.

9. Barakat K, Wilkinson P, Suliman A, Ranjadayalan K, Timmis A. Acute myocardial infarction in women: contribution of treatment variables to adverse outcome. Am Heart J. 2000;140:740 -746.

10. Chandra NC, Ziegelstein RC, Rogers WJ, Tiefenbrunn AJ, Gore JM, French WJ, Rubison M. Observations of the treatment of women in the United States with myocardial infarction: a report from the National Registry of Myocardial Infarction-I. Arch Intern Med. 1998;158:981-988.

11. Thygesen K, Alpert JS, Jaffe AS, et al. Third universal definition of myocardial infarction. Circulation. 2012;126:2020-35. 
12. Killip T, Kimball JT . Treatment of myocardial infarction in a coronary care unit. A two year experience with 250 patient. Am J Cardio1967. 20 (4): 457-64.

13. O'Gara PT, Kushner FG, Deborah D et al. 2013 ACCF/AHA Guideline for the Management of STElevation Myocardial Infarction: A Report of the American College of Cardiology Foundation/American Heart Association Task Force on Practice Guidelines. Circulation. 2013; 127:e362-e425.

14. Adhikari CM, Bhatta YD, Malla R et al. Outcomes of Primary Percutaneous Coronary Intervention at Shahid Gangalal National Heart Centre, Kathmandu, Nepal. Journal of Advances in internal Medicine. 2012;2(1):6-9.

15. Parajuli M, Maskey A, Kohli S C, Shrestha UK . Gender Difference in Frequency of Conventional Risk Factors in Patients with Acute Coronary Syndrome Admitted in Manipal Teaching Hospital, Pokhara, Nepal. Nepal Journal of Medical Sciences. 2012;1(1):31-34.

16. Paudel B, Paudel Kl. Western Nepal acute coronary syndrome (WestNP-ACS) registry: Characteristics, management and in- hospital outcome of patients admitted with acute coronary syndrome in western Nepal. Journal of GMC-Nepal. 2009;2(3):51-59.

17. Milcent C, Dormont B, Durand-Zaleski I et al. Gender Differences in Hospital Mortality and Use of Percutaneous Coronary Intervention in Acute Myocardial Infarction Microsimulation Analysis of the 1999 Nationwide French Hospitals Database. Circulation. 2007;115:833-839.

18. Butt Z, Shahbag U, Hashmi AT, et al. Frequency of conventional risk factors in patients with acute coronary syndrome in males and females. ANNALS 2010;16:558.
19. McKinley S, Dracup K, Moser DK, et al. International comparison of factors associated with delay in presentation for AMI treatment. Eur J Cardiovasc Nurs. 2004;3:225-230.

20. Malhotra S, Gupta M, Chandra KK, Grover A, Pandhi P. Prehospital delay in patients hospitalized with acute myocardial infarction in the emergency unit of a North Indian tertiary care hospital. Indian Heart Journal .2003; 55(4):349-353.

21. Vaccarino V, Rathore SS, Wenger NK et al. Sex and Racial Differences in the Management of Acute Myocardial Infarction, 1994 through 2002. N Engl J Med 2005;353:671-82.

22. Malacrida R, Genoni M, Maggioni AP, Spataro V, Parish S, Palmer A, Collins R, Moccetti T, for the third International Study of Infarct Survival collaborative group. A comparison of the early outcome of acute myocardial infarction in women and men. $\mathrm{N}$ Engl J Med 1998;338:8-14.

23. Tunstall-Pedoe H, Morrison C, Woodward M, Fitzpatrick B, Watt G. Sex differences in myocardial infarction and coronary deaths in the Scottish MONICA population of Glasgow 1985 to 1991. Circulation 1996;93:1981- 1992.

24. Lee KL, Woodlief LH, Topol EJ, Weaver D, Betrin A, Col J, Simoons M, Aylward P, Van der Werf F, Califf RM, for the GUSTO-I Investigators. Predictors of 30-day mortality in the era of reperfusion for acute myocardial infarction. Circulation 1995;91:1659-1668.

25. Kudenchuk PJ, Maynard C, Martin JS, Wirkus M, Weaver WD. Comparison of presentation, treatment, and outcome of acute myocardial infarction in men versus women (The Myocardial Infarction Triage and Intervention Registry). Am J Cardiol 1996;78:9-14.

Correspondence Addresss: Dr. Hemant Shrestha, DM Resident, Department of Cardiology, Manmohan cardiothoracic vascular and transplant center, Institute of medicine, Tribhuvan University, E-mail: drhemantshrestha@gmail.com 